\title{
ФИЛОСОФСКО-МИРОВОЗЗРЕНЧЕСКИЕ ОСНОВЫ ЭКОНОМИЧЕСКИХ ОТНОШЕНИЙ В ИСЛАМЕ
}

\section{PHILOSOPHICAL AND IDEOLOGICAL FUNDAMENTALS OF ECONOMIC RELATIONS IN ISLAM}

\section{Yu. Yaroslavtseva}

Summary: This article analyzes the key foundations of religious and ethical principles of economic relations in Islam. It is proved that the worldview is usually understood as a set of beliefs about the fundamental aspects of reality that justify and influence all our perception, thinking, knowledge and actions.

The first part of this article offers a precise definition and the nature of the worldview and why it is necessary, with a brief analysis of modern paradigms of worldviews. The second part presents an understanding of the basic principles of an integrated Islamic worldview in the light of the Koran and hadith.

Due to the limitations of this article and in order to avoid a lengthy discussion of the terminology or content of the worldview, i.e. epistemology, metaphysics, cosmology, teleology, theology, anthropology and axiology, which are strongly interrelated with each other, were not discussed in this article intentionally.

Keywords: Islamic banking, Islamic finance, muhakala, munabaza, zakat, riba, garar, sharia law, haram, maysir.
Ярославцева Юлия Олеговна

Аспирант, Российская академия народного хозяйства и государственной службы при Президенте РФ (РАНХИГС) vostok.rf2014@yandex.ru

Аннотация: В настоящей статье проанализированы ключевые основы религиозно-этических принципов экономических отношений в Исламе. Доказано, что мировоззрение обычно понимается как набор убеждений о фундаментальных аспектах реальности, которые обосновывают и влияют на все наше восприятие, мышление, знание и действия.

В первой части данной статьи предлагается точное определение и природа мировоззрения и почему оно необходимо, с кратким анализом современных парадигм мировоззрений. Вторая часть представляет понимание основных принципов интегрированного исламского мировоззрения в свете Корана и хадисов.

Ввиду ограничений данной статьи и во избежание длительного обсуждения терминологии или содержания мировоззрения, т.е. эпистемология, метафизика, космология, телеология, теология, антропология и аксиология, которые сильно взаимосвязаны друг с другом, не обсуждались в этой статье намеренно.

Ключевые слова: исламский банкинг, исламские финансы, мухакаля, мунабаза, закят, риба, гарар, закон шариата, харам, майсир. $\ni$ кономическая история человеческой цивилизации является интересными многомерным явлением, уходит своими корнями вглубь веков; охватывает, объединяет и разделяет истории целых народов и континентов, эпохи, культуры и нации. Современная экономика рыночного типа является неоспоримым результатом многотысячелетнего синтеза опыта целых народов и их цивилизационных центров. Хотя экономика как самостоятельный вид деятельности существует с незапамятных времен, а как отрасль науки - сотни лет, глобальная проблема несоответствия между материальными потребностями общества и духовно-мировоззренческой парадигмой, сформированной ведущими мировыми религиями - с другой, остается так и не решенной в планетарном масштабе.

Термин мировоззрение (Weltanschauung на немецком языке), как система взглядов, оценок и образных представлений о мире и месте в нём человека сформирован еще И. Кантом (1724-1804). Данная формулировка использовалась и используется не только в философии, но и в других областях социальных наук.
Термин мировоззрение, к сожалению, часто используется без каких-либо точных указаний. Что же такое мировоззрение? Как мы можем это определить? Философами было предложено множество различных определений (например, Кантом (1724-1804), Гегелем (17701831), Кьеркегором (1813-1855), Дильтеем (1833-1911), Гуссерлем (1859-1938, Ясперсом (1883-1969), Хайдеггером (1889-1976).

Проведение исторического сравнения разного мировоззрения выходит за рамки данной статьи. Вместо этого ограничимся анализом четкого и плодотворного определения, предложенного западными и Исламскими учеными, о которых расскажем в первой части. Вторая часть анализа предоставит понимание исламского мировоззрения в части экономических отношений. Очевидно, что два понятия - «философия» и «мировоззрение» тесно связаны.

Философия - это гипотетическая интерпретация неизвестного (как в метафизике) или неточно известного (как в этике или политической философии). Термин «мировоззрение» часто используется, чтобы подчеркнуть 
личную и историческую точку зрения. В этом смысле термин может иметь отрицательное значение. Однако можно определить класс философских мировоззрений, основанных на рациональности и, следовательно, нацеленных на своего рода универсальную значимость.

Мировоззрение - это набор убеждений о фундаментальных аспектах реальности, которые лежат в основе и влияют на все восприятие, мышление, знание и действия. Это исследование мира; взгляд на жизнь; буквально восприятие мира; особая философия жизни; концепция мира, которой придерживается человек или группа людей.

Мировоззрение относится к общей концепции природы мира, в частности, как содержащей или подразумевающей систему ценностных принципов. Любая философская система в целом может иметь такой стиль, который выводит практические следствия из ее теоретического компонента.

Согласно этим определениям, такая система ценностных принципов может быть вдохновлена религиозными принципами или моральной философией, независимой от религии. Кроме того, отличительные духовные и материальные аспекты жизни общества и человека часто в конечном итоге формируют их мировоззрение.

Поэтому, делая выбор, очень важно смотреть на мировоззрение, динамику с точки зрения различных социальных систем. У людей в обществе могут быть собственные принципы или вариации, но их стандартное поведение было бы склонно к общественно согласованным нормам.

Как было рассмотрено выше, мировоззрение - это набор убеждений о фундаментальных аспектах реальности, которые обосновывают и влияют на все восприятие, мышление, знание и действия. Мировоззрение также называется философией, философией жизни, мировоззрением и взглядами на жизнь, формулой жизни, идеологией, верой или даже религией.

Мировоззрение можно рассматривать как эволюционное и архитектоническое - относящиеся к классификации знаний, используемых в метафизике, а не контекстуальное. Социальные явления ярки, и из-за взаимодействия между меняющимися реальностями жизни и восприятием социального мировоззрения последнее неизменно имеет временное измерение. Таким образом, мировоззрение остается в процессе изменения и реконструкции с течением времени вокруг некоторых неизменных элементов, поскольку оно исходит от людей, тогда они также начинают думать о религиозном мировоззрении, таком как исламское мировоззрение.
Исламское мировоззрение (IWV) в основном теистическое и этическое мировоззрение, которое резко контрастирует с секуляристской или атеистической альтернативой. Это мировоззрение проистекает из фундаментальной веры в то, что жизнь и существование возникли в результате воли, желания и замысла Единого Создателя. Таким образом, исламская концепция Бога должна предшествовать любым дискуссиям о природе вселенной и отношении человека к ней.

Исламское мировоззрение - это всеобъемлющая концепция вселенной и отношения человека к ней с исламской точки зрения, тем самым служащая основой для философии или взглядов на жизнь. Видение реальности и истины, которое появляется перед нашим мысленным взором, раскрывая суть существования; ведь это мир существования во всей его полноте, который проецирует Ислам.

В свете вышеизложенного можно сказать, что в исламском мировоззрении раздвоения мира нет. Нет двойственности. Исламское мировоззрение основано на двух основных источниках: Коране, который мусульмане считают прямым словом Бога, и Сунне, включающей традиции, касающиеся жизненного примера Пророка Мухаммеда. Однако ядром обоих является принцип Таухад, который мотивирует все, что есть в исламской религиозной мысли.

Религия должна иметь общественный имидж не только для того, чтобы демонстрировать духовность ради нее, но и для того, чтобы позволить отдельному человеку и обществу в целом искать руководство в своих поступках для повседневной жизни. Таким образом, Исламское мировоззрение (IWV) направляет человека на путь как наместника Аллаха.

Исламское мировоззрение простое и легкое для понимания и рационализации. Оно основано на трех фундаментальных принципах: таухад (теизм), хилафа (наместничество) и адалах (справедливость). Эти принципы не только составляют основу исламского мировоззрения, но и составляют основу макасидов (целей) и стратегии жизни человека в этом мире.

Таким образом, не может быть и речи о лоскутном одеяле или запоздалой реакции на противоречивые требования плюралистических групп или социальных классов. Единство Аллаха суммирует исламский образ жизни и представляет его виде конкретного руководства для всех мусульман.

Принцип Таухида закладывает основу исламского социального порядка, который учит человека, что его социально-экономическая деятельность должна руководствоваться принципами из единого общего источника, 
Аллаха (Субханахува Та'ала). Этот единый общий источник раскрывает свои принципы в Священном Коране.

Кораническое учение Таухуда и его объяснения концепция Бога и Его атрибутов предназначена для того, чтобы позволить людям вырваться из оков невежества и устойчивых обычаев, и традиций, которые не гарантируют вечного спасения. Именно это учение Коран предлагает человечеству, чтобы оно руководствовалось абсолютно правильным образом. Именно это делает Коран с абсолютной уверенностью в своей эффективности в предоставлении людям окончательного руководства.

Сегодня глобальным научно-практическим приоритетом общества является поиск эффективных моделей экономического устройства жизни человека. Синергетическая взаимодействие экономической теории и хозяйственной практики постепенно сняли остроту обозначенной выше проблемы, однако отнюдь не решили ее в полной мере.

Поиск новых гипотетических факторов экономического роста и попытка «имплантировать» их в общую конструкцию здания мировой экономики - передний фронт современной экономической науки. Развитие институционального направления теоретической экономики ознаменовался включением в модели экономического устройства общества таких, на первый взгляд, иррациональных, «неэкономических» компонентов, как обычаи, культура, религия, традиции, чувства, инстинкты, эмоции, совокупно создавали альтернативную рациональной экономики концепцию ее эффективного обустройство и развития.

Сакральные по своей сути вероисповедания и культура, по нашему мнению, среди определенных выше факторов-гипотез экономического развития является чрезвычайно влиятельными и заслуживающими более глубокого исследования и всесторонней компаративной аналитики. Они хотя и не предлагают исчерпывающих ответов на вопросы о том, как увеличить объем общественного производства, уменьшить инфляцию, сократить безработицу или добиться экономического процветания, однако они в значительной степени формируют поведенческие мотивы, как индивида, так и целого народа, обусловливают наше поведение, преференции, выбор и, наконец, формируют экономическую составляющую нашей ментальности.

Поучительное обращение Пророка к своим последователям (11:85) звучит как обязательная к исполнению установка и оно касается не только торгово-экономических отношений, но и де-факто защищает институт частной собственности - базовую и обязательную компоненту современной рыночной конструкции.
«О, мой народ! Соблюдай честно меру и вес;

Имуществу людей не наносите ущерба,

И злодеяний не было никаких на земле

Вы не делайте посевом нечисти и смуты».

Экономика ислама выступает явлением, оказывающим влияние на общество, на его модели поведения, принципы, нормы и мировоззрение. Соотношение религиозного мировоззрения и экономической системы в современном мире - данные вопросы касаются любой мировой религии, причем позиции религиозного духовенство на протяжении времени отличались друг от друга: от строгого и неукоснительного соблюдения всех религиозных предписаний в экономическом поведении до признания, обоснования возможности более гибкого подхода в отношении финансовой жизни верующих людей.

В современном мире вторая точка зрения становится все более усиливающейся тенденцией. По мнению О. Шпенглера: «В экономической истории всякой культуры происходит отчаянная борьба, которую ведут против денег, коренящаяся в почве традиция расы, её душа». Социально-экономическая доктрина в исламе сформировалась в ранний период мусульманства, при этом Ислам на протяжении тысячелетий сумел отстоять нравственный императив в отношении финансово-хозяйственной деятельности своих последователей и неукоснительно следовал своим мировоззренческим основам.

В мировоззренческую картину ислама встроен очень важный фактор. Он оказывает специальное влияние на деятельность правоверных мусульман, связанную с финансово-экономической составляющей. К ней преимущественное количество зарубежных и отечественных авторов относят: в первую очередь, «справедливость (добропорядочность). А во-вторую - нравственное наполнение распоряжения экономическими ресурсами (собственностью и деньгами)» [4]. Отметим, что, многие принципы экономических отношений, которые до настоящего времени строго соблюдаемы шариатским законом, были заложены и в мировоззренческие основы и других религий, например, в православии.

Религиозно-этические нормы экономических отношений в Исламе выражаются в некоторых видах ограничений:

- запрет на несправедливость в сделках. «Горе обвешивающим, которые хотят получить сполна, когда люди отмеривают им, а когда сами мерят или взвешивают для других, то наносят им урон» Коран (83:1-3);

- запрете на неопределенность условий в сделке (посланник Аллаха - Ахмад наставлял: «Не покупайте рыбу в воде, которая ещё не поймана, так как в этом присутствует гарар»);

- запрет на ростовщичество (запрет на рибу); 
- запрет на участие в неразрешенных видах деятельности. «Они спрашивают тебя о вине и азартных играх. Скажи: «в них есть большой грех» [9].

Рассмотрим подробнее философско-религиозные основы этих видов ограничений, составляющих основу религиозно-этических норм каждого мусульманина.

\section{I. Запрет на несправедливость в слелках}

Одна из основных мировоззренческих основ исламской экономики - принцип справедливости. Этические основы исламских финансов отличаются от общеэкономических основ, прежде всего, пониманием высшего блага в справедливом распределении ресурсов, транспорентности экономических отношений и строгим соблюдением условий договоров. «Ведущая основа богобоязненности и приближения к Божественной Истине - справедливость. Вероятно, истоки данного принципа исходят из античной философии и в частности трудов Аристотеля» [4].

\section{Религиозные принципы ислама}

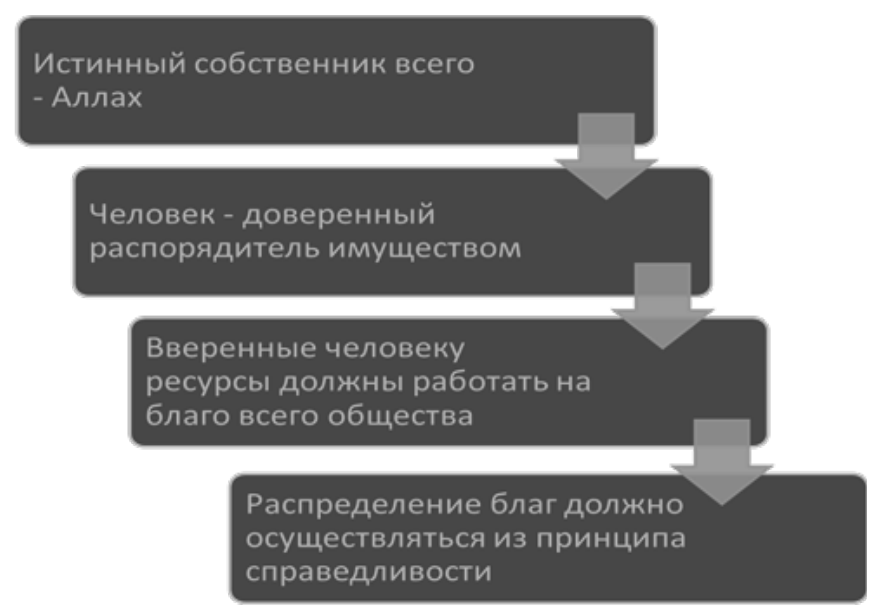

Согласно Корану: «О, вы, которые уверовали! Будьте стойки [в вере вашей] в Бога, выступайте свидетелями справедливости. И пусть ненависть ваша к кому-либо не ведет Вас к пристрастию. Будьте привержены справедливости, ибо ближе она к богобоязненности. Страшитесь Всевышнего, ведь ведает Он о том, что вершите вы» (Коран, 5:8). Согласно исламской доктрине, «справедливость является главным условием достижения принципа равенства в обществе. Справедливость - одна из главных божественных установок» (Коран, 49:9). Благодаря этому мировоззренческому принципу ислам определяет себе ведущую роль в установлении экономического миропорядка.

Шариат не запрещает прибыль в купле-продаже и не определяет конкретный размер данной прибыли, но запрещает обман, мошенничество, восхваление в товаре качества, которых в нем нет, или скрывать имеющийся в нём дефект. Таким образом, религия склоняет общество к транспарентному ведению финансово-хозяйственных дел. В современной жизни запрет на несправедливость в сделках также воплощается в недопустимости обмана (например, в части качества и реальной стоимости товара/услуги), в недопустимости действий спекулятивного характера.

Кроме того, монополизм и олигопольный сговор тоже относятся к несправедливому поведению по отношению к другим лицам, присутствующим на рынке. Также, справедливое перераспределение материальных благ происходит путем обязательных пожертвований уммы в виде закята (благотворительного взноса), таким образом, уравновешивается баланс между бедными и богатыми представителями мусульманского сообщества

\section{II. Запрет на неопределенность условий в слелке}

Под данное понятие попадают так называемые гарарные сделки. Гарар можно трактовать как необоснованный, повышенный риск или спекулятивные сделки. В исламской экономике контракт результат, которого не определен, является недопустимым, виды неопределенности в рамках контракта можно разделить на следующие категории. Соблюдение прав и выгод каждого представителя сделки лежит в основе мировоззренческой картины исламских финансов.

Таким образом, в современном мире любые биржевые и фьючерсные контракты подпадают под этот вид ограничений, кроме того, например, классический механизм страхования становится запретным при соблюдении данных норм Шариата.

Во-первых, в страховании по западной экономической модели присутствует неопределённость (гарар), поскольку заранее неизвестно, получит ли клиент компенсацию.

Во-вторых, в классическом страховании есть элемент случайно полученной прибыли - майсир. Одна из сторон рассчитывает получить возмещение в денежной форме, которое в несколько раз превышает величину его взноса.

В-третьих, в механизме страхования могут присутствовать скрытые процентные сделки, если страховая фирма зарабатывает свою прибыль путем размещения денежных средств под депозиты. В данном случае исламская экономика предлагает свою альтернативу классическому страхованию в виде такафула (исламского страхования), в рамках которого не используются запретные механизмы функционирования.

Религиозно мировоззренческие истоки данного запрета выражается в необходимости строгого соблюде- 
ния условий договорных отношений в исламе, а значит в необходимости сохранения верности данному слову. При присутствии факторов неопределенности, сокрытия информации или объективных рисках всестороннее соблюдение условий договорных отношений становится труднодостижимым. К тому же, верность данному слову (соблюдение договоренностей), согласно исламской этике, является основополагающим принципом религиозного мировоззрения.

Это доказывают некоторые айаты Корана: «[истинно] благочестив тот, кто уверовал в Бога, в день судный, в ангелов, Писание, пророков, [благочестивы] верные данной ими клятве» (Коран, 2:177); «Воистину, помнят [об этом] лишь мужи разумные, которые тверды в Завете, заключенном с Богом, и не нарушают его» (Коран, 13:19-20).

Абу Бакр, первый халиф мусульман, в своих наставлениях воинам ислама говорил: «Пусть в ваших соглашениях с врагом не останется места для обмана и лжи. Всегда во всём будьте правдивы и докажите, что вы люди честные и достойные. Дорожите данным словом».

Согласно преданию, Джа'фар ас-Садик, шестой имам мусульман, говорил: «Есть три вещи, которыми Всевышний Господь никому не позволил пренебрегать: первое - обеспечение сохранности доверенного имущества, независимо от того, благодетелен ли его владелец или нет; второе - верность данному обещанию в отношении как с праведными, так и неправедными людьми; третье благодеяние по отношению к родителям, независимо от того, праведны они или нет».

\section{III. Запрет на ссудный прочент или запрет на рибу}

Ростовщичество активно практиковалось у арабов доисламской эпохи в виде процента за пользования займом, а также виде дополнительных платежей за просрочку срока возврата займа. Ссудный процент - риба, согласно исламу, считается, прибавкой к одному из однородных предметов обмена, и при этом у этой прибавки нет никакой компенсации [1].

С установлением Ислама в мусульманском сообществе ситуация изменилась. «О, вы, которые уверовали! Не живите за счет лихвы, удвоенной или многократной, бойтесь Аллаха, и, быть может, преуспеете вы» [9]. Данным айятом подчеркивается пагубное влияние ростовщичества, поскольку оно может истощить деньги должников, и со временем от накопления долговой нагрузки, они оказываются в отчаянном положении от бедности и безысходности, не имеющими никаких надежд в этой жизни из-за такого бесчеловечного обращения, и в этом явный вред самой цивилизации.

Поскольку Всевышний завещал богатым бедных, которым он дал явное право на их состояние и узаконил долг для помощи страдающим нуждой [1]. Очевидно, что с точки зрения мировоззренческих основ, данный вид запрета продиктован гуманистическими соображениями, стремлением стимулировать финансово-хозяйственный рост, и присутствует во многих религиях виде пожеланий и рекомендаций к поведению верующего человека. Однако, согласно Исламу, это наиболее строжайший запрет, который неоднократно упомянут в Коране. «Искореняет Аллах лихву и поощряет подаяние. Не любит Он грешника неблагодарного» [1].

\section{Нешелесообразность прочентной ставки с точки зрения исламских финансов}
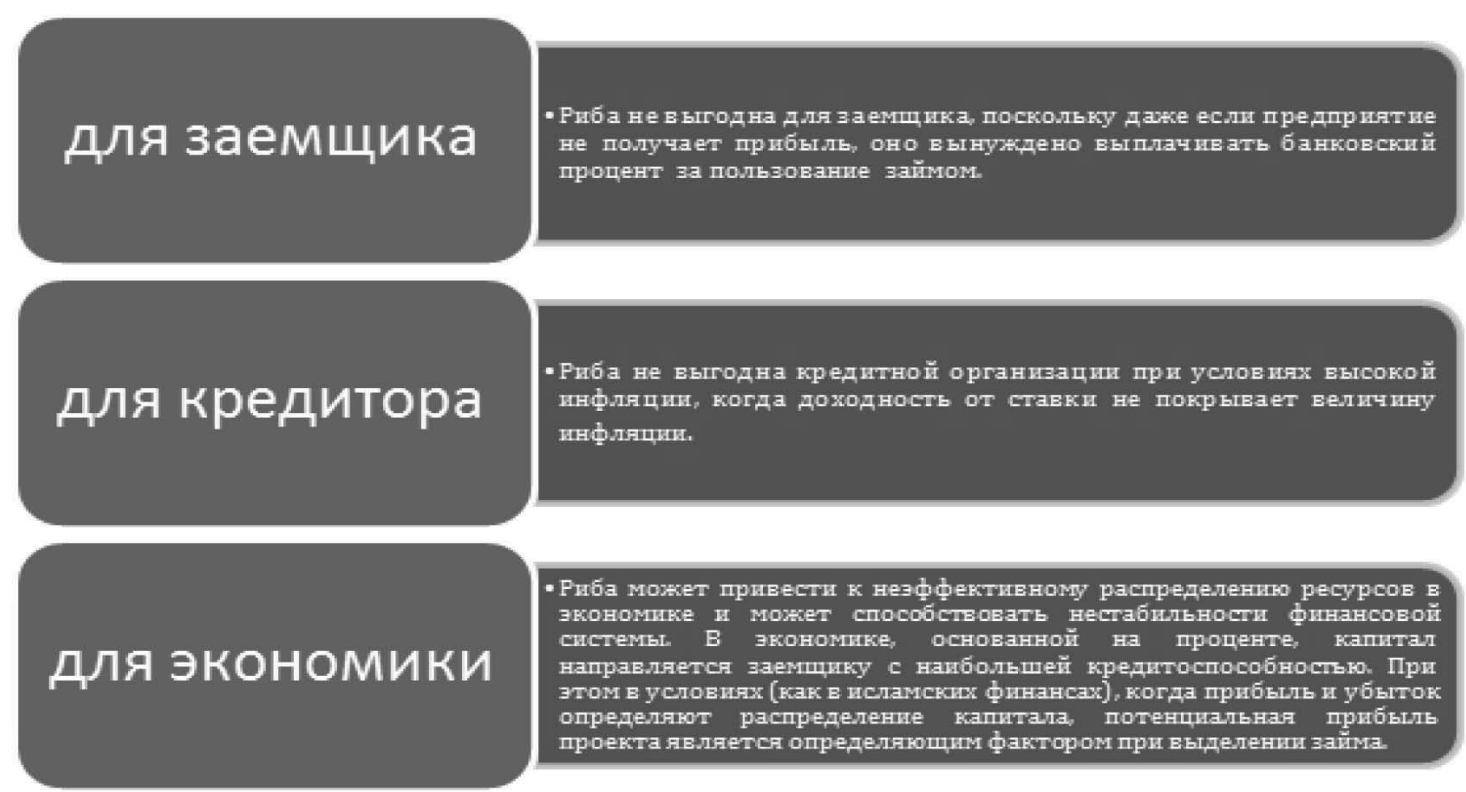

- Риба может привести к неэффективному распределенаю ресурсов в экономике и может способствовать нестабильности финансовой системег $\mathrm{B}$ экономике, основанной на проденте, капнтал натравлнетсп эаемщику с нанбольшей креднтоспособностю. Прп направлнетсн эаемщику с нанбольшей креднтоспособностько. При

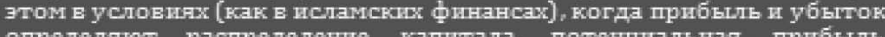

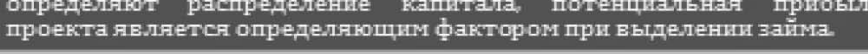


В рамках этого ограничения действует не только механизм недопустимости увеличения долговой нагрузки путем взимания процента от заемной суммы. «Сюда же включены штрафы по неисполнению условий возврата заемной суммы. Следовательно, любой долг, который влечет за собой прибыль, рассматривается как ростовщичество» [10].

Таким образом, исламская экономика опирается на рационализм даже в большей степени, чем классическая Европейская, подчеркивая, что кредитование пагубно для всего общества в целом, ведет к рискам банкротств и возникновению финансовых пузырей.

\section{IV. Запрет на участие в неразрешенных видах Аеятельности}

Запрет на участие в неразрешенных видах деятельностях, харамный вид заработка, создает ограничения по видам предпринимательской деятельности дозволенной мусульманину. Плюс, различные проявления коррупции; преступны группировки и формирования. Данные виды заработка могут опорочить любого приверженца Ислама в глазах религиозного сообщества. Запретным является не только производство вредоносного, но и участие в торговли.

При этом, сама торговля считается богоугодным видом заработка. По словам исламского правоведа Aхмада ат-Табарини, лучшая нажива - честная торговля и когда человек работает своими руками. Под честной торговлей подразумевается торговать дозволенными товарами и услугами, не предавать и не ослушиваться Аллаха при её ведении. Необходимо, чтобы предмет сделки был ритуально чистым и дозволенным, также недопустимо использовать в качестве предмета оплаты за товар вино или свинину, такая сделка считается недействительной [1]. Указания в части харамных видов деятельности не подлежит изменению на протя- жении всей истории Ислама и соблюдается с целью сохранения порядка в обществе, а также для соблюдения законодательных норм.

Таким образом, важнейшей задачей шариата является обеспечение благополучия людей, которое основывается на сохранении религиозных, нравственных и этических норм. Все это закладывается в основу мировоззрения мусульманина, любая деятельность, наносящая вред этому мировоззрению строго ограничивается шариатом.

Главная идея соблюдения столь жестких религиозномировоззренческих принципов заключается в том, чтобы объединить исламское общество единой моралью, едиными законами, а также стимулировать экономический рост и соблюдение нормативно-правового порядка в религиозном обществе.

Вместе с тем основные задачи сформированного мировоззрения заключаются в следующем:

- обеспечивать всем верующим равноправные возможности;

- создать положительную атмосферу для духовного роста и саморазвития;

- обеспечить справедливое распределение материальных ресурсов в социуме;

- сохранять экономический порядок и стабильное экономическое возрастание.

Эти категории, а также, исключение харамных видов деятельности обусловили, с одной стороны, безопасную предпринимательскую среду.

Таким образом, выстроенная мусульманами исламская экономическая система (исламский банкинг, исламское страхование и прочее) способствуют сохранению исламских ценностей и объединению исламского сообщества на основе единого мировоззрения.

\section{ЛИТЕРАТУРА}

1. Абд ар-Рахман ибн Мухаммад Авад аль-Джузайри Законы торговли в четырех мазхабах // Издательство ДИЛЯ. - 2017. - с. 174 - 182

2. Natalie Schoon Modern Islamic banking // John Wiley \& Sons Ltd. - 2016. - c. 44-47.

3. Edited by M Kabir Hassan / Mamunur Rashid Islamic corporate finance // Printed in the United Kingdom by Henry Ling Limited. - 2019. - c. 123 - 128.

4. Коран

5. Игнатова Т.В. Система «Хавала» в исламской экономике// Мусульманский мир. - 2017. - № 2. - С. 39-52.

6. Стогов Д.И. Ислам: история и современность: учеб.пособие по дисциплине «Религиоведение» // Санкт-Петербургский государственный электротехнический университет им. В.У. Ленина - 2018. - № 2. - с. 28-36

7. Мингатин М.Г. понимание того, что запрещено (харам) в финансовых структурах // современный мусульманский мир - 2019. - № 1. - с. 1-12

8. Шамиль Аляутдинов Подсознательные бедность и богатство // Издательство ДИЛЯ. - 2018. - c. 96 - 112

9. Коран Риполклассик / Москва. // отв. ред. Пороховой И.В / 2012

10. Имам Абу Хамид аль-ГазалиАдабы // Издательство Хузур-Спокойствие - 2020. -с.47- 64.

() Ярославцева Юлия Олеговна (vostok.rf2014@yandex.ru). 